\title{
International Summit on Laparoscopic Pancreatic Resection (ISLPR)
}

\section{"Coimbatore Summit Statements"}

C. Palanivelu*, Kyoichi Takaori*, Mohd Abu Hilal*, David A. Kooby**, Go Wakabayashi**, Anil Agarwal, Stefano Berti, Marc Besselink, Kuo Hsin Chen, Andrew A. Gumbs, , Ho-Seong Han, Goro Honda, Min Zheng Hua, Igor Khatkov, Hong Jin Kim, Igor Khatkov, Jiang Tao Li, Tran Cong Duy Long, Marcel Machado, Akira Matsushita, Krish Menon, Masafumi Nakamura, Yuichi Nagakawa, Juan Pekolj, Ignasi Poves, Shahidur Rahman, Liu Rong, Antonio Sa

Cunha, P. Senthilnathan, Shailesh V. Shrikhande, S. Srivatsan Gurumurthy, Dong Sup Yoon, Yoo-Seok Yoon, Vijay Khatri**

(*C Palanivelu, K Takaori, and M Abu Hilal have contributed equally to the scientific content of this paper. ${ }^{*}$ Critical evaluation of the manuscript was done by D Kooby, G Wakabayashi, and V Khatri.)

Correspondences: Prof. C. PALANIVELU, Director \& Head of the Department of Surgical Gastroenterology, Gem Hospital and Research Centre, Coimbatore, India

palanivelu@mac.com 


\section{History and evolution of Laparoscopic pancreatic resection (LPR):}

A technique of laparoscopic pancreaticoduodenectomy (LPD) was first reported by Gagner and Pomp in 1994. While the technique was feasible, the postoperative course was complicated by delayed gastric emptying and early reports concluded that LPD may not improve the postoperative outcomes or shorten the postoperative recovery period $(1,2)$. Following these initial reports, the technique of LPD was further refined as presented at the Society of American Gastrointestinal and Endoscopic Surgeons (SAGES) conference in Atlanta in 2000 and at the World Congress of Endoscopic Surgeons (WCES) in Singapore in 2000 by Palanivelu. Subsequently, the first successful large (>50) series of LPD was reported by Palanivelu's group in 2009 (3). More recently, Kendrick and Cusati reported another successful large series of LPD and concluded that LPD is feasible, safe, and effective (4). However, due to technical difficulties especially with the reconstruction portion of the procedure, the technique of LPD was reserved for highly skilled laparoscopic surgeons until today. In contrast, laparoscopic distal pancreatectomy (LDP) is less demanding than LPD and consequently it was not long before LDP became popular with satisfactory results in many countries. Numerous meta analyses have shown that LDP is associated with less blood loss, lower blood transfusion rates, lower wound infection rates, lower morbidity rates, and shorter hospital stays when compared to open surgery (5-7). Unlike other laparoscopic surgery, pancreatic 
resections are routinely performed at a limited number of specialized centers (810). While LDP for non-invasive lesions is regarded as gold standard at many institutions, wider adoption of LDP for malignancy and LPD in general include has been limited due to the complexity of the surgical technique, proximity to major vessels, high post-operative morbidity rate and lack of a standardized technique.

\section{Genesis of ISLPR}

At the postgraduate course during the $11^{\text {th }}$ World Congress of International Hepato-Pancreato-Biliary Association (IHPBA) in Seoul in 2014, many surgeons expressed keen interests in the techniques of laparoscopic pancreatic resection. Combined with the aforementioned complicating factors, the enthusiasm necessitated an expert meeting of laparoscopic and robotic pancreatic surgeons. Consequently, the State-of-the-Art Conference on Minimally Invasive Pancreatic Resection (MIPR) was held with participation of over 400 attendees during the $12^{\text {th }}$ World Congress of IHPBA in Sao Paulo in 2016. In this conference, it was pointed out that while existing literature may show promise, it was too early to prove the value of MIPR over open pancreatic resection, especially for a pancreaticoduodenectomy. As a consequence, this seminal event set the stage for future meetings (11). Since operative and technical themes were not pursued in the State-of-the-Art Conference in Sao Paulo (11), several expert pancreatic surgeons expressed interests in gathering 
again to formulate another meeting to specifically discuss the technical aspects of MIPR. Hence, the International Summit on Laparoscopic Pancreatic Resection (ISLPR) in Coimbatore, India, was proposed and international experts who regularly perform laparoscopic pancreatic resections were invited. 30 surgeons from four continents, i.e., South and North America, Europe and Asia, agreed to participate in ISLPR. The first conversation of ISPLR was made online on August 26th, 2016 and the structures of the summit were developed. As a process for interactive discussion, the experts were requested to complete an online questionnaire about the various technical aspects of laparoscopic pancreatic resections. Two further web-based meetings were conducted prior to the main summit that was subsequently held in Coimbatore, India on $7^{\text {th }}$ and 8th of October, 2016.

\section{Aims of ISLPR}

To establish guidelines for laparoscopic pancreatic resections, we developed objectives for the ISLPR which were:

I. To identify indications and optimal case selection criteria for MIPR in the setting of both benign and malignant diseases $(3,12,13)$.

II. Standardization of techniques to increase the safety of $\operatorname{MIPR}(3,4,14)$.

III. Identification of common problems faced during MIPR and developing associated management strategies $(15,16)$. 
IV. Development of clinical protocols to allow early identification of complications and develop the accompanying management plan to minimize morbidity and mortality (17-19).

V. Development of structured training programs to promote safe expansion of MIPR among dedicated surgeons across the globe $(20,21)$.

\section{ISLPR Survey}

A questionnaire consisting of sixty-five questions covering the following aspects of MIPR were sent to representative experts across the globe:

$>\quad$ Indications and case selection

$>\quad$ Resection techniques

$>\quad$ Reconstruction techniques

$>\quad$ Peri-operative outcomes

$>\quad$ Training and credentials

All participants of ISLPR as well as other MIPR experts who were not able to physically attend the main summit in Coimbatore participated in this survey. The results of the survey were discussed during the main summit. The survey results can be viewed at this link http://www.surveymonkey.com/results/SMZ7VYS6YX

Representative data of the survey are shown in Figures 1-5. 


\section{ISLPR Expert Committee Meeting: Initial Agreements}

The experts who gathered at the ISPLR exchanged their knowledge and experiences during a symposium on 8th of October, 2016. Next day, the Expert Committee Meeting (ECM) was held where all experts were present. At the start of the ECM, there was unanimous agreement on the following four issues.

I. There exists a need for clear guidelines for the safe expansion of laparoscopic pancreatic surgery.

II. A Delphi method will be used for the production of the guidelines in order to produce a consensus opinion from the experts.

III. Working groups will be formulated and each group will be allocated a topic for development.

IV. We will cover the cardinal topics of Disease, Implementation, Patients, Techniques, and Instrumentations (DIPTI) and use the Delphi approach for the future projects.

\section{ISLPR: Coimbatore Summit Statements}

The preliminary discussion during the ISLPR resulted in the formation of initial statements, which will be further developed by the experts for the establishment of final guidelines. The initial statements are described hereafter and we hereby publish them as Coimbatore Summit Statements. 


\section{The Disease (D)-}

1. In expert hands, lesion size should not be a limiting factor for LPD, either by conventional laparoscopic or robotic surgery $(7,22)$. However, it was agreed that lesions $>3 \mathrm{~cm}$ should not be considered for LPD during the early phase of the learning curve

2. Non-complicated ampullary lesions and pancreatic head lesions remote from the SMA and SMV are best indications to learn proper technique of LPD. Major vascular resection is feasible in the hands of selected experts $(23,24)$, but this does not yet apply to the majority of cases or majority of surgeons.

3. During the early part of the learning curve ampullary tumors / small distal cholangiocarcinomas, neuro-endocrine tumors and cystic tumors are most suitable for laparoscopic resection with the caveat that pancreatic leak rate after pancreaticoduodenectomy may be higher due to the higher percentage of soft pancreas in this subset of patients (25-28). This is important to note as the fistula rate may be falsely elevated in this group of patients undergoing LPD when compared to historical controls of open pancreatic surgery.

\section{Patients (P)}

4. Age is not a contraindication for LPD, provided the indication for surgery has been discussed by a Multi-Disciplinary Team and a plan developed. 
5. High body mass index (BMI) is not a contraindication for LPD. However, surgeons should avoid operating on obese patients in the early phase of their learning curve, with the understanding that obesity, in fact, may become an indication for MIPR in the future.

6. Indication for a MIPR approach should be based solely on pathology and the patient's overall fitness.

7. Previous pancreatitis is not a contraindication for MIPR. However, it is associated with increased technical difficulty and should be avoided in the early phase of the learning curve.

\section{Implementation (I)}

8. Multiple techniques currently exist and standardization of these approaches is currently lacking.(12, 29-31).

9. Pre-operative biliary drainage is not a contra-indication for LPD. However, it may be associated with technical difficulties.

10. Previous abdominal surgery is not a contra-indication for LPD.

\section{Instrumentation (I)}

11. Future expansion of MIPR will continue to depend on a strong partnership between clinicians and the medical industry. The summit agreed that a variety of 
instruments have been developed over the last 2 decades to facilitate the accomplishment of MIPR. These include:

- High definition optics

- Instruments for precise dissection

- Vascular control methods

- Instruments for parenchymal division

- Sutures

- Hemostasis

- Handheld and sterilizable robotics $(22,32,33)$

\section{Techniques (T)}

The ECM agreed that the bottom line is safe development and implementation of MIPR. After interactive deliberations, the ECM agreed upon the following aspects of technique of MIPR:

12. MIPR should only be undertaken by surgeons with a broad experience in both advanced laparoscopy and pancreatic resection.

13. Surgeons should train in centers of excellence. Proctoring must be an integral part of the implementation of a new service.(34) 
14. Surgeons should be trained using a step-wise approach, starting with LDP prior to performing $\operatorname{LPD}(29,35)$.

In addition, the following technical factors were also discussed:

- Port placement

- Patient position

- Pancreatic exposure and mobilization; e.g., an anterior approach, a posterior approach, and artery-first approaches $(36,37)$

- Different technical approaches

- Methods of parenchymal division

- Methods of vascular control

- Methods of pancreatic reconstruction

- Management of the stump

We acknowledged that there are many technical variations in these factors and that future studies are needed to determine the best or better techniques. Until then, each surgeon may utilize their preferable techniques which work best for them. 
As conclusions of the ECM in Coimbatore, fundamental recommendations as following were proposed with unanimous agreement.

I. MIPR should be performed only in centers with wide experiences in pancreatic surgery.

II. MIPR should be considered as standard practice for distal pancreatectomy.

III. Rather than a large association with broad focuses, a specific society for minimally invasive pancreatic surgery may help move this field further. It should have the aim of ensuring the safe expansion of MIPR.

IV. The specific society should work in harmony with existing associations toward the same aims and targets and may function under the umbrella of large associations.

\section{Perspectives}

The Coimbatore Summit Statements were created by expert surgeons who practice MIPR on a daily basis. ISPLR was unique as compared to prior conceptual meetings, in terms of the intensive interests in the technical aspects of the operation. At the end of the summit on 8th October 2016, the attending experts agreed upon the formation of a group of task forces for future guidelines. Also agreed at the ECM was the plan to establish the specific, albeit small, society that focuses on MIPR and would welcome all experts across the globe to join. This specific society will readily collaborate with larger associations such 
as IHPBA and International Association of Surgeons Gastroenterologists and Oncologists. It may also be a good option to use existing platforms such as the Society of International Pancreatic Endoscopic Surgeons (SIPES), which was originally founded by pioneers in 2005 (38). All these issues will be discussed and determined in the future meetings where more experts will be able to attend.

\section{Acknowledgement:}

We duly acknowledge the contributions of Dr. S. Srivatsan Gurumurthy, Dr.

Dhawal Sharma, Dr. N. Anand Vijai, Dr. V.P. Nalankilli, Dr. Sandeep Sabnis, Dr. S. Rajapandian, Dr. R. Parthasarathi, Dr. P. Praveen Raj, \& Dr. P. Senthilnathan along with the entire team of doctors and staff of Gem Hospital, for successful organisation of this landmark ISLPR in Coimbatore, India.

\section{References}

1. Gagner M, Pomp A. Laparoscopic pylorus-preserving pancreatoduodenectomy. Surg Endosc. 1994 May;8(5):408-10.

2. Gagner M, Pomp A, Herrera MF. Early experience with laparoscopic resections of islet cell tumors. Surgery. $1996 \mathrm{Dec} ; 120(6): 1051-4$.

3. Palanivelu C, Rajan PS, Rangarajan M, Vaithiswaran V, Senthilnathan P, Parthasarathi $\mathrm{R}$, et al. Evolution in techniques of laparoscopic pancreaticoduodenectomy: a decade long experience from a tertiary center. $J$ Hepatobiliary Pancreat Surg. 2009;16(6):731-40.

4. Kendrick ML, Cusati D. Total laparoscopic pancreaticoduodenectomy: feasibility and outcome in an early experience. Arch Surg. 2010 Jan;145(1):19-23.

5. Kooby DA, Gillespie T, Bentrem D, Nakeeb A, Schmidt MC, Merchant NB, et al. Leftsided pancreatectomy: a multicenter comparison of laparoscopic and open approaches. Ann Surg. 2008;248(3):438-46.

6. Nakamura Y, Uchida E, Aimoto T, Matsumoto S, Yoshida H, Tajiri T. Clinical outcome of laparoscopic distal pancreatectomy. J Hepatobiliary Pancreat Surg. 2009;16(1):35-41. 
7. Asbun HJ, Stauffer JA. Laparoscopic vs open pancreaticoduodenectomy: overall outcomes and severity of complications using the Accordion Severity Grading System. J Am Coll Surg. 2012 Dec;215(6):810-9.

8. Croome KP, Farnell MB, Que FG, Reid-Lombardo KM, Truty MJ, Nagorney DM, et al. Total laparoscopic pancreaticoduodenectomy for pancreatic ductal adenocarcinoma: oncologic advantages over open approaches? Ann Surg. 2014 Oct;260(4):633-8; discussion $8-40$.

9. Senthilnathan P, Srivatsan Gurumurthy S, Gul SI, Sabnis S, Natesan AV, Palanisamy $\mathrm{NV}$, et al. Long-term results of laparoscopic pancreaticoduodenectomy for pancreatic and periampullary cancer-experience of 130 cases from a tertiary-care center in South India. $J$ Laparoendosc Adv Surg Tech A. 2015 Apr;25(4):295-300.

10. Stauffer JA, Coppola A, Villacreses D, Mody K, Johnson E, Li Z, et al. Laparoscopic versus open pancreaticoduodenectomy for pancreatic adenocarcinoma: long-term results at a single institution. Surg Endosc. 2016 Sep 07.

11. Vollmer CM, Asbun HJ, Barkun J, Besselink MG, Boggi U, Conlon KC, et al. Proceedings of the first international state-of-the-art conference on minimally-invasive pancreatic resection (MIPR). HPB. 2017;8(17):015.

12. Merchant NB, Parikh AA, Kooby DA. Should all distal pancreatectomies be performed laparoscopically? Adv Surg. 2009;43:283-300.

13. Fisher SB, Kooby DA. Laparoscopic pancreatectomy for malignancy. J Surg Oncol. 2013 Jan;107(1):39-50.

14. de Rooij T, Sitarz R, Busch OR, Besselink MG, Abu Hilal M. Technical Aspects of Laparoscopic Distal Pancreatectomy for Benign and Malignant Disease: Review of the Literature. Gastroenterol Res Pract. 2015;2015:472906.

15. Abu Hilal M, Richardson JR, de Rooij T, Dimovska E, Al-Saati H, Besselink MG. Laparoscopic radical 'no-touch' left pancreatosplenectomy for pancreatic ductal adenocarcinoma: technique and results. Surg Endosc. 2016 Sep;30(9):3830-8.

16. Sahakyan MA, Kazaryan AM, Rawashdeh M, Fuks D, Shmavonyan M, Haugvik SP, et al. Laparoscopic distal pancreatectomy for pancreatic ductal adenocarcinoma: results of a multicenter cohort study on 196 patients. Surg Endosc. 2016 Aug;30(8):3409-18.

17. Riviere D, Gurusamy KS, Kooby DA, Vollmer CM, Besselink MG, Davidson BR, et al. Laparoscopic versus open distal pancreatectomy for pancreatic cancer. Cochrane Database Syst Rev. 2016 Apr 04;4:CD011391.

18. de Rooij T, van Hilst J, Busch OR, Dijkgraaf MG, Kooby DA, Abu Hilal M, et al. Laparoscopic Distal Pancreatectomy for Pancreatic Ductal Adenocarcinoma: Time for a Randomized Controlled Trial? Results of an All-inclusive National Observational Study. Ann Surg. 2016 Mar 11.

19. Palanivelu C, Senthilnathan P, Sabnis SC, Babu NS, Srivatsan Gurumurthy S, Anand Vijai N, et al. Randomized clinical trial of laparoscopic versus open pancreatoduodenectomy for periampullary tumours. Br J Surg. 2017;104(11):1443-50.

20. Gumbs AA, Gayet B. The Medical and Surgical Department of Digestive Diseases and Minimally Invasive HPB Fellowship at IMM. HPB (Oxford). 2007;9(6):470-1.

21. Hogg ME, Besselink MG, Clavien PA, Fingerhut A, Jeyarajah DR, Kooby DA, et al. Training in Minimally Invasive Pancreatic Resections: a paradigm shift away from "See one, Do one, Teach one". HPB. 2017;19(3):234-45.

22. Gumbs AA, Croner R, Rodriguez A, Zuker N, Perrakis A, Gayet B. 200 consecutive laparoscopic pancreatic resections performed with a robotically controlled laparoscope holder. Surg Endosc. 2013 Oct;27(10):3781-91.

23. Kendrick ML, Sclabas GM. Major venous resection during total laparoscopic pancreaticoduodenectomy. HPB (Oxford). 2011 Jul;13(7):454-8.

24. Palanisamy S, Deuri B, Naidu SB, Vaiyapurigoundar Palanisamy N, Natesan AV, Palanivelu PR, et al. Major venous resection and reconstruction using a minimally invasive approach during laparoscopic pancreaticoduodenectomy: One step forward. Asian J Endosc Surg. 2015;8(4):468-72. 
25. Gumbs AA, Gres P, Madureira FA, Gayet B. Laparoscopic vs. open resection of noninvasive intraductal pancreatic mucinous neoplasms. J Gastrointest Surg. 2008 Apr;12(4):707-12.

26. Gumbs AA, Gres P, Madureira F, Gayet B. Laparoscopic vs open resection of pancreatic endocrine neoplasms: single institution's experience over 14 years. Langenbecks Arch Surg. 2008 May;393(3):391-5.

27. Gumbs AA, Jarufe N, Gayet B. Minimally invasive approaches to extrapancreatic cholangiocarcinoma. Surg Endosc. 2013 Feb;27(2):406-14.

28. Senthilnathan P, Chinnusamy P, Ramanujam A, Sivakumar SG, Natesan AV, Chandramaliteeswaran C, et al. Comparison of Pathological Radicality between Open and Laparoscopic Pancreaticoduodenectomy in a Tertiary Centre. Indian J Surg Oncol. 2015;6(1):20-5.

29. Gumbs AA, Gayet B. The laparoscopic duodenopancreatectomy: the posterior approach. Surg Endosc. 2008 Feb;22(2):539-40.

30. Asbun HJ, Stauffer JA. Laparoscopic approach to distal and subtotal pancreatectomy: a clockwise technique. Surg Endosc. 2011 Aug;25(8):2643-9.

31. Abu Hilal M, Takhar AS. Laparoscopic left pancreatectomy: current concepts. Pancreatology. 2013 Jul-Aug;13(4):443-8.

32. Giulianotti PC, Sbrana F, Bianco FM, Elli EF, Shah G, Addeo P, et al. Robot-assisted laparoscopic pancreatic surgery: single-surgeon experience. Surg Endosc. 2010;24(7):164657.

33. Milone L, Daskalaki D, Wang X, Giulianotti PC. State of the art of robotic pancreatic surgery. World J Surg. $2013 \mathrm{Dec} ; 37(12): 2761-70$.

34. de Rooij T, van Hilst J, Boerma D, Bonsing BA, Daams F, van Dam RM, et al. Impact of a Nationwide Training Program in Minimally Invasive Distal Pancreatectomy (LAELAPS). Ann Surg. 2016;264(5):754-62.

35. Speicher PJ, Nussbaum DP, White RR, Zani S, Mosca PJ, Blazer DG, et al. Defining the Learning Curve for Team-Based Laparoscopic Pancreaticoduodenectomy. Annals of Surgical Oncology. [journal article]. 2014;21(12):4014-9.

36. Sanjay P, Takaori K, Govil S, Shrikhande SV, Windsor JA. 'Artery-first' approaches to pancreatoduodenectomy. Br J Surg. 2012;99(8):1027-35.

37. Takaori K, Uemoto S. Artery-First Distal Pancreatectomy. Dig Surg. 2016;33(4):3149.

38. Takaori K, Tanigawa N. Laparoscopic pancreatic resection: the past, present, and future. Surg Today. 2007;37(7):535-45.

Figure legends:

Fig 1. Representative data of ISPLR Survey: Size criteria.

Fig 2. Representative data of ISPLR Survey: Tumor location.

Fig 3. Representative data of ISPLR Survey: Tumor type/pathology.

Fig 4. Representative data of ISPLR Survey: Size criteria: Disease stage.

Fig 5. Representative data of ISPLR Survey: Size criteria: Upper age limit. 
Do you have a tumour size criteria for choosing cases for LPD?

Answered: 4h skipped: 0

3 to $5 \mathrm{~cm}$

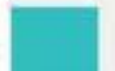

be povison up

Other (ploase
specty)

os $10 \mathrm{~s} 20 \% \mathrm{~s}$ sos

Let sos

coss row $00 \mathrm{~s}$. $90 \mathrm{~s} 100 \mathrm{~N}$

\begin{tabular}{l|l|l|}
\hline Anisarer Choices & Rocponses & 15 \\
\hline Leas then $3 \mathrm{em}$ & $34.09 \%$ & 3 \\
\hline $3105 \mathrm{~cm}$ & $11.36 \%$ & 17 \\
\hline Any size may be taken up for LPD & $36.04 \%$ & 7 \\
\hline Other fiplease specily? & $15.91 \%$ & Respomes \\
\hline
\end{tabular}

Fig 1. 
Does the location of tumor influence your decision of taking up patients for LPD?

(More than one option may be chosen)

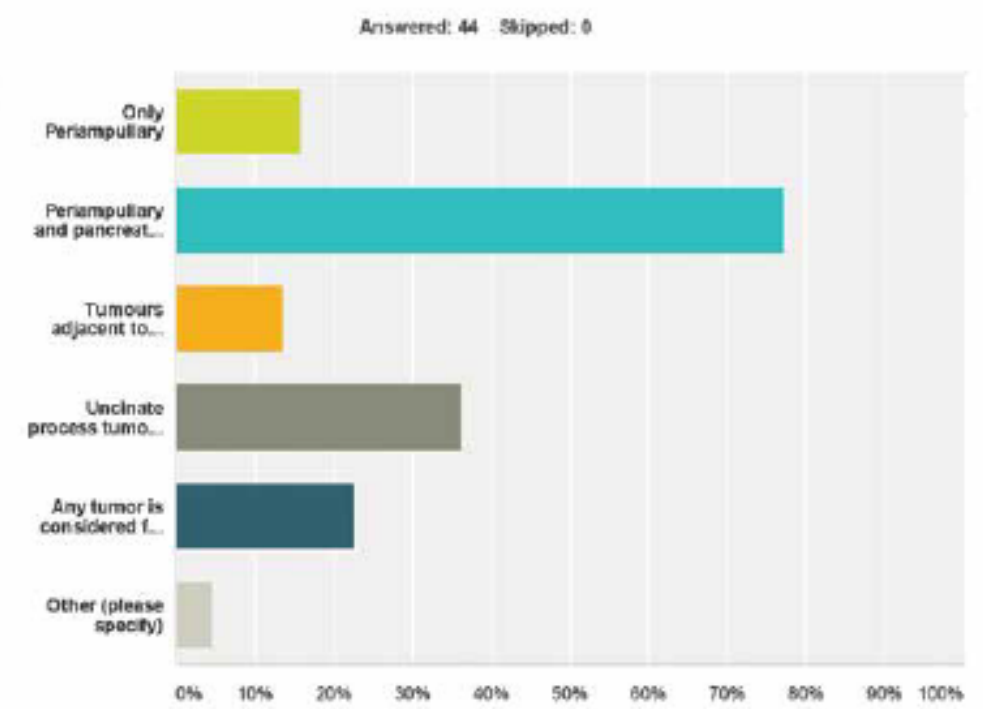

$7727 \%$

Fig. 2 
Does the tumor type/pathology influence your decision of choosing LPD? (More than one option may be chosen)

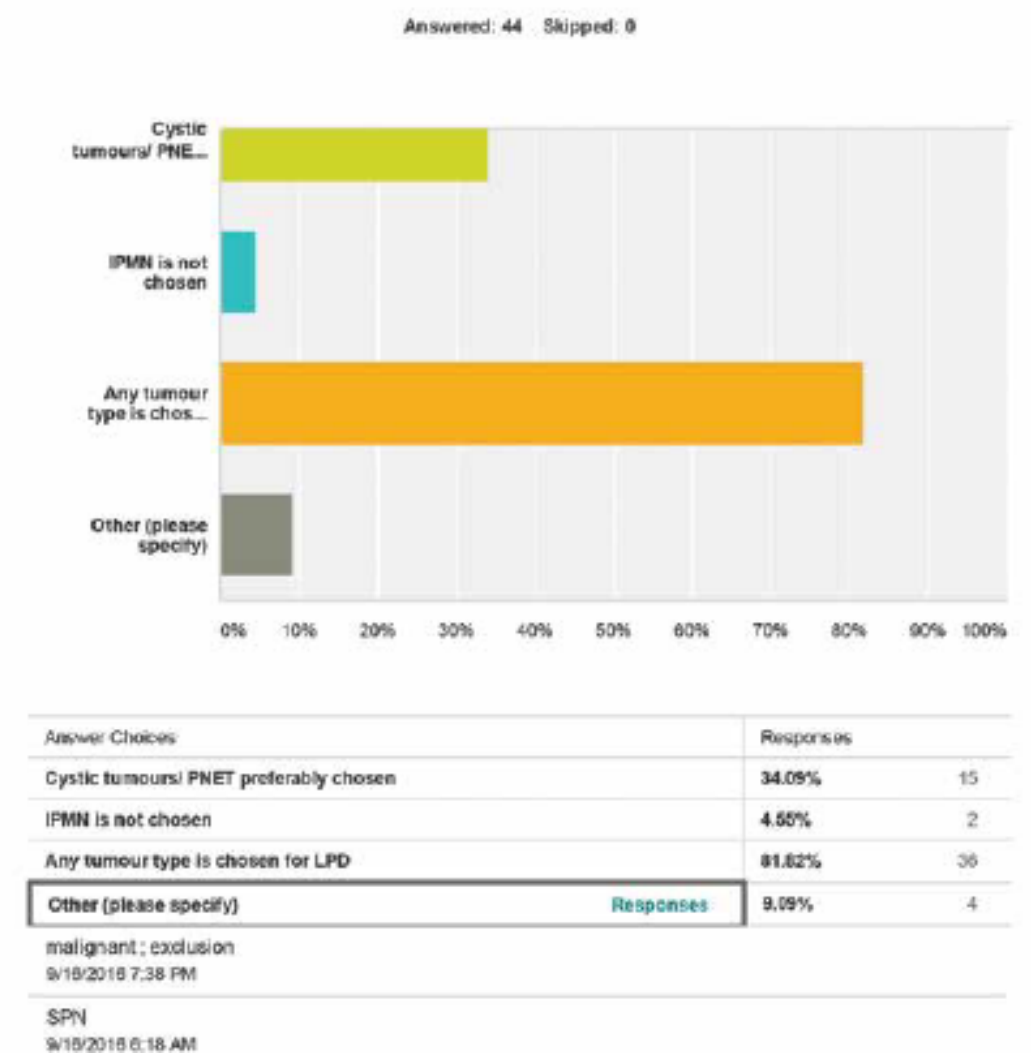

Fig 3. 
Does the preoperative stage of tumour

influence your decision on choosing

patients for LPD

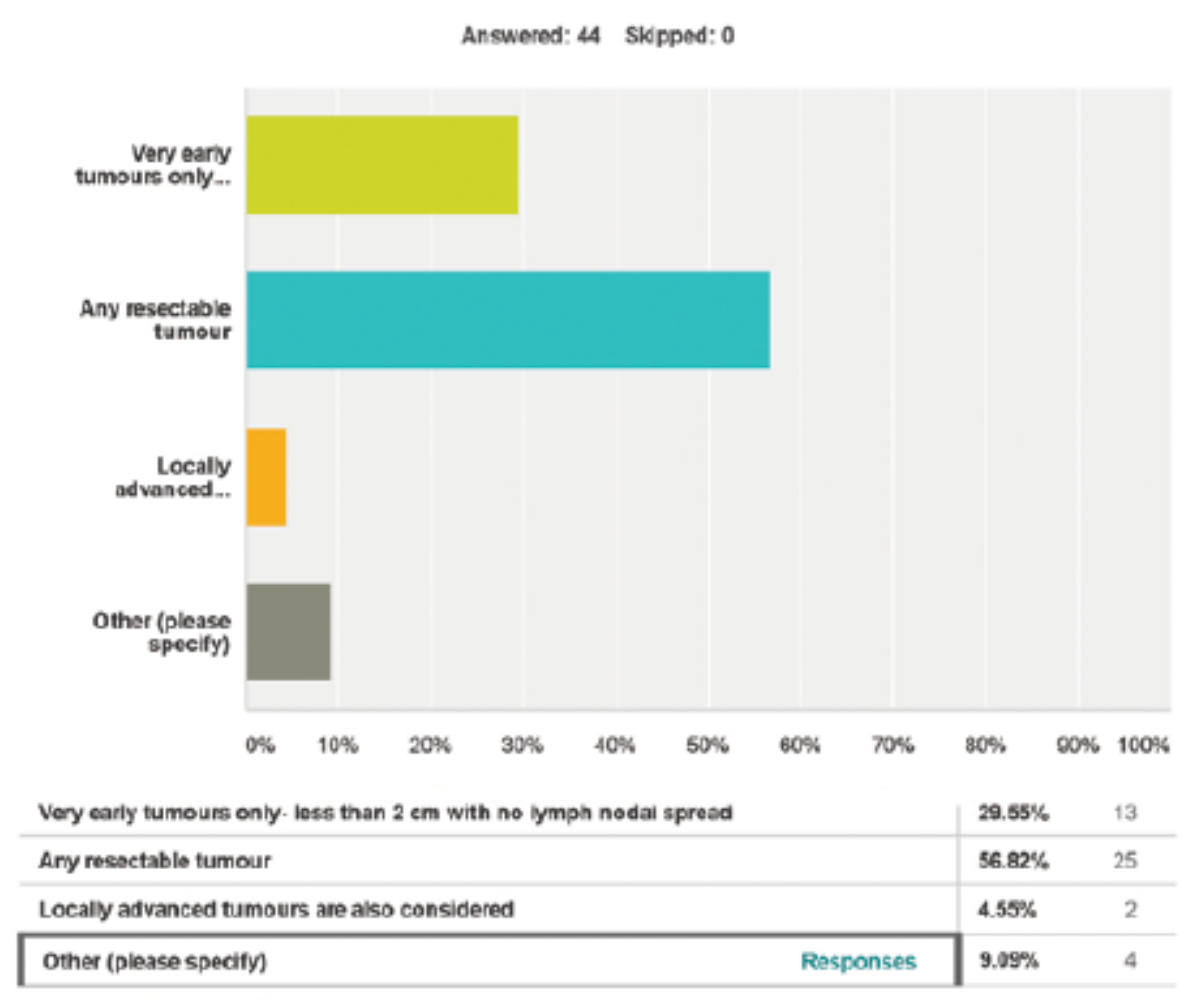

Fig. 4 


\section{Do you have an upper age limit for choosing cases for LPD}

Answered: 44 skipped: 0

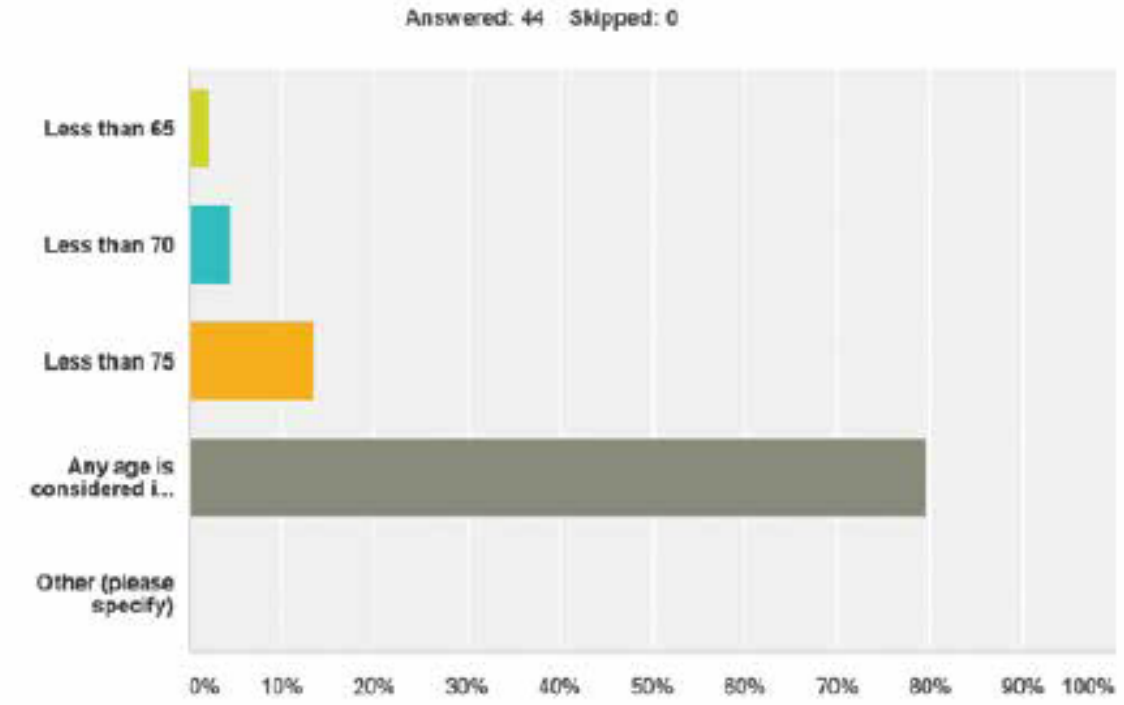

\begin{tabular}{|c|c|}
\hline Answer Choikes & Responses \\
\hline Less than 65 & $2.27 \%$ \\
\hline Less than 70 & $4.55 \%$ \\
\hline Less than 75 & $13,64 \%$ \\
\hline Any age is considered if performance status is good & $79.55 \%$ \\
\hline
\end{tabular}

Fig 5. 